\title{
Article \\ Association of Depression and Anxiety with Social Network Types: Results from a Community Cohort Study
}

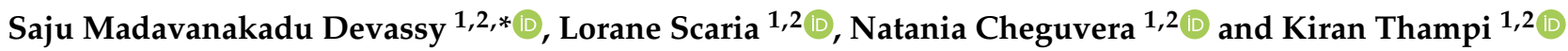 \\ 1 Rajagiri College of Social Sciences (Autonomous), Kerala 683 104, India; lorane@rajagiri.edu (L.S.); \\ nataniamicheal@gmail.com (N.C.); kiranthampis@rajagiri.edu (K.T.) \\ 2 Rajagiri International Centre for Consortium Research in Social Care (ICRS), Kerala 683 104, India \\ * Correspondence: saju@rajagiri.edu
}

Citation: Devassy, S.M.; Scaria, L.;

Cheguvera, N.; Thampi, K.

Association of Depression and

Anxiety with Social Network Types: Results from a Community Cohort

Study. Int. J. Environ. Res. Public

Health 2021, 18, 6120. https://

doi.org/10.3390/ijerph18116120

Academic Editor: Paul B. Tchounwou

Received: 10 May 2021

Accepted: 5 June 2021

Published: 6 June 2021

Publisher's Note: MDPI stays neutral with regard to jurisdictional claims in published maps and institutional affiliations.

Copyright: (c) 2021 by the authors. Licensee MDPI, Basel, Switzerland. This article is an open access article distributed under the terms and conditions of the Creative Commons Attribution (CC BY) license (https:/ / creativecommons.org/licenses/by/ $4.0 /)$

\begin{abstract}
Social networks protect individuals from mental health conditions of depression and anxiety. The association between each social network type and its mental health implications in the Indian population remains unclear. The study aims to determine the association of depression and anxiety with different social network types in the participants of a community cohort. We conducted a cross-sectional household survey among people aged $\geq 30$ years in geographically defined catchment areas of Kerala, India. We used cross-culturally validated assessment tools to measure depression, anxiety and social networks. An educated male belonging to higher income quartiles, without any disability, within a family dependent network has lower odds of depression and anxiety. Furthermore, 28, 26.8, 25.7, 9.8 and 9.7\% of participants belonged to private restricted, locally integrated, wider community-focused, family-dependent and locally self-contained networks, respectively. Close ties with family, neighbours, and community had significantly lower odds of anxiety and depression than private restricted networks. The clustering of people to each social network type and its associated mental health conditions can inform social network-based public health interventions to optimize positive health outcomes in the community cohort.
\end{abstract}

Keywords: depression; anxiety; social network types; mental health; India

\section{Introduction}

In India, 197 million people have reported a prevalence of mental disorders. Of these, 45.7 million had depressive disorders, and 44.9 million had anxiety disorders [1]. A study examining the global burden of disease (GBD) estimated that the prevalence of anxiety and depression in India was 3.3\% (3-3.5\%) and 3.3\% (3.1-3.6\%), respectively [1]. The World Health Organization (WHO) predicted that by 2020, approximately $20 \%$ of Indians would develop mental illnesses [2]. Furthermore, a study examining GBD reported that among all Indian states, Kerala had the highest prevalence of both depression and anxiety. Mental health conditions, such as depression and anxiety, among populations worldwide are affected by social networks. Studies report an undeniable association between the mental health of people and the type of social network they belong to [3-6].

\subsection{Social Networks as Protective Factors for Mental Health}

Social networks are the systems of social relationships in which an individual embeds $[7,8]$. An individual's social network consists of people with whom they regularly interact, the characteristics of such individuals and the quality of interactions. A support network is defined as the availability and accessibility to formal and informal platforms of social interactions. Individuals with limited support networks have lower levels of mental health and psychological wellbeing [3]. The feeling of being loved and cared for was associated with lower levels of anxiety, depression and somatization, and better adaptation to stressful situations [9]. Strong support networks can reduce the prevalence of mental health conditions. Support networks can provide physical and psychological advantages 
to people who encounter stressful events and reduce psychological distress [10]. Social integration is the extent to which individuals participate in various social relationships, including engagement in social activities or relationships, and a sense of commonality and identification with one's social roles [11]. Low social integration is associated with poor health outcomes, including those related to mental health.

The present study is part of a more extensive cohort study called SWADES (social wellbeing and determinants of health study) [12] and aimed to determine depression and anxiety with support network types in participants included in the cohort. This study adopted Wenger's concept of social network typology [13], which includes five distinct support network types. Each type represents different levels of integration into society, and the extent of support received within the social network.

\subsection{Social Network Typologies}

The five social network types are as follows: family-dependent, locally integrated, locally self-contained, wider community-focused and private restricted. These social network types bases on the following criteria:

- proximity to close kin;

- proportion of family, friends, and neighbours involved;

- levels of interactions between people and their families, friends, neighbours, and community groups.

Wenger reported that individuals in family-dependent or private restricted support networks have the highest risk of loneliness, depression and other mental health conditions. In contrast, those in a locally integrated network have a lower risk of adverse mental health outcomes [14]. Furthermore, people in private restricted or locally self-contained networks had a higher risk of isolation than those in locally integrated or wider community-focused support networks [14].

Various studies have demonstrated a causal relationship between mental health and social network typologies, wherein social networks protect individuals from mental health issues such as depression [15-19]. Although studies have extensively examined the association between mental health and social networks, we used Wenger's social network typology in this study to determine support networks among individuals aged $\geq 30$ years. Previous studies conducted in India have used Wenger's social network typology only in older adults. Studies have rarely explored the association between each social network type and its mental health implications in Indian individuals aged $\geq 30$ years. This study will follow up the cohort over ten years to determine whether social networks change with changes in individual profiles in India and how these changes modulate participants' mental health outcomes.

\section{Materials and Methods}

We conducted a cross-sectional household survey among people aged $\geq 30$ years. The findings of this study used data from the SWADES, a more extensive cohort study in Keezhmad panchayat located in the Vazhakulam block of Ernakulam district, Kerala. We interviewed a total of 997 participants in this survey at their homes.

We selected Keezhumadu Panchayath as the geographical location for data collection as it represents a mixed culture and a cross-section of socioeconomic characteristics of people in Kerala. We did a mapping exercise to geographically mark the boundaries and locate all the households with a participant aged above 30 . The study is part of the SWADES cohort study, focusing on chronic conditions and mental health comorbidities in communities. For the study, we included inclusion criteria of 30 years and above for the participants, as chronic conditions and other comorbidities are usually seen among people aged 30 and above [20]. Trained postgraduate students conducted door to door surveys to identify the outcome variables through a structured questionnaire comprising standardized scales. All the questions were administered in the local language, Malayalam, by the students. Students obtained informed consent from all the participants before 
participation. A study protocol previously published [12] describes the recruitment of sample and further procedures in detail.

\subsection{Measures}

\subsubsection{Outcome Variables}

The two primary outcomes measured were depression and anxiety. We assessed depression and anxiety using the Depression, Anxiety and Stress Scale (DASS), a self-report instrument [21]. DASS-42 is a set of three scales that separately measure depression, anxiety and stress. Each item evaluates the frequency of depressive or anxiety symptoms during the past week on a 4-point scale, with a score of $0,1,2$, and 3 indicating rarely or none of the time, some of the time, much of the time, and most or all the time, respectively.

Scores for depression and anxiety were calculated by summing scores obtained for relevant items. Based on summative scores, the depression level of participants was categorised as normal (0-9), mild (10-13), moderate (14-20), severe (21-27), and extreme $(28+)$. Similarly, anxiety was categorised as normal (0-7), mild (8-9), moderate (10-14), severe (15-19), and extreme (20+). This study considered an individual to have depression or anxiety if the DASS score was moderate or above. The cut-off scores for anxiety and depression determined using the DASS scale have been validated previously [20]. Studies conducted across India on common mental health conditions have used the DASS as a valid and reliable measure of depression, anxiety and stress. Cronbach internal consistency of the entire scale was 0.89. [22-24].

\subsubsection{Social Network Variables}

The Practitioner Assessment of Network Type (PANT) described by Wenger was employed to ascertain the social network types of participants $[8,13]$. The construct validity of Wenger's social network typology was tested and validated in an Indian setting [14]. The questionnaire includes the following eight questions:

- How far away does your nearest relative live? 0 (no relatives); 1 (with $1.6 \mathrm{~km} / \mathrm{same}$ home); 2 (1.5-9.6 km); $3(9.7-25.7 \mathrm{~km}) ; 4(25.8-80.5 \mathrm{~km}) ; 5$ (above $80.5 \mathrm{~km})$

- Where does your nearest sister or brother live? 0 (no siblings); 1 (with $1.6 \mathrm{~km} / \mathrm{same}$ home); 2 (1.5-9.6 km); 3 (9.7-25.7 km); 4 (25.8-80.5 km); 5 (above $80.5 \mathrm{~km})$

- Where does your nearest child live? 0 (no child); 1 (with $1.6 \mathrm{~km} /$ same home); 2 (1.5-9.6 km); $3(9.7-25.7 \mathrm{~km}) ; 4$ (25.8-80.5 km); 5 (above $80.5 \mathrm{~km}$ )

- How often do you see any of your children or relatives to speak to? 0 (never); 1 (daily); 2 (2-3 times a week); 3 (at least weekly); 4 (at least monthly); 5 (less often)

- How often do you have a chat or do something with one of your friends? 0 (never); 1 (daily); 2 (2-3 times a week); 3 (at least weekly); 4 (at least monthly); 5 (less often)

- How often do you see any of your neighbours to have a chat or do something with? 0 (never); 1 (daily); 2 (2-3 times a week); 3 (at least weekly); 4 (at least monthly); 5 (less often)

- Do you attend religious meetings/visit religious places? 0 (no); 1 (yes, regularly); 2 (yes, occasionally)

- Do you attend meetings of any community or groups such as clubs, lectures or anything like that? 0 (no); 1 (yes, regularly); 2 (yes, occasionally)

Five network typologies, namely family-dependent, locally integrated, locally selfcontained, wider community-focused and private restricted types, are described based on participant responses to the above questions. The five network types in detail include:

- A family-dependent network type is a network type predominantly characterised by (a) a relative living within a $1.6 \mathrm{~km}$ radius; (b) a child and/or sibling living within a radius of $9.6 \mathrm{~km}$; (c) frequent contact with a relative (daily or 2-3 times a week); (d) limited contacts with friends or neighbours (never, less often or at least monthly); (e) and occasional attendance to religious meeting and community clubs.

- A locally integrated network type is characterised by (a) close proximity with a relative (living within the same house, within a radius of $9.6 \mathrm{~km}$ and/or within 
$25.7 \mathrm{~km}$ ); (b) a child and/or sibling living close (within the same house, within a radius $9.6 \mathrm{~km}$ and/or a radius of $25.7 \mathrm{~km}$ ); (c) very frequent contact with a relative (daily and/or 2-3 times a week); (d) frequent contacts with neighbours and/or friends (daily, 2-3 times a week and/or at least weekly); (e) regular attendance at religious meetings and community clubs.

- A locally self-contained network type is characterised by (a) an arm's length proximity with relatives (living within a radius of $25.7 \mathrm{~km}$ and/or a radius of $80.5 \mathrm{~km}$ ), children (no child, a child living within a radius of $25.7 \mathrm{~km}$ and/or a radius of $80.5 \mathrm{~km}$ ) and siblings (living within a radius of $9.6 \mathrm{~km}$ and/or $25.7 \mathrm{~km}$ and/or $80.5 \mathrm{~km}$ ); (b) occasional contact with relatives (at least weekly and/or at least monthly) and neighbours (at least weekly and/or at least monthly); (c) limited contact with friends (less often and / or at least monthly) and (d) occasional attendance at religious meetings and/or community clubs.

- A wider community focused network type is network type predominantly characterised by (a) absence of a relative (living within a radius of $80.5 \mathrm{~km}$ or above), child (living within a radius of $80.5 \mathrm{~km}$ or above or a sibling (living within a radius of $80.5 \mathrm{~km}$ or above; (b) limited contacts with relatives (less often and/or at least monthly); (c) occasional contacts with neighbours (at least weekly and/or at least monthly); (d) very frequent contact with friends (daily, 2-3 times a week and /or at least weekly) and regular attendance at clubs and religious meetings.

- A private restricted network is characterised by (a) lack of relatives (living within a radius of $80.5 \mathrm{~km}$ or above), child (living within a radius of $80.5 \mathrm{~km}$ or above) or siblings (living within a radius of $80.5 \mathrm{~km}$ or above); (b) minimal contact with relatives, friends or neighbours (less often) and (c) no involvement in religious meetings or clubs.

Physical proximity and frequency of communication are two important factors used by Wenger to identify the social networks in the PANT Social network questionnaire. Proximity is a fundamental way for people to connect, as a person tends to approach someone close to them rather than someone distant in the hour of need [25]. This is especially true in India, where the likelihood of travelling considerable distances are limited due to several reasons including limited public/private transport, poor and narrow roads, heavy traffic or rising fuel costs [26]. The exact algorithm used to construct the network variable has been described in detail in another study [13].

Private restricted social network characterised by little involvement in activities or relationships are identified as nonintegrated social networks. In contrast, social networks with good relationships and/or involvement in activities are identified as integrated social networks.

\subsubsection{Sociodemographic Variables}

We used a questionnaire to collect the following sociodemographic information of participants: age, sex, education, occupation and income. Chronic diseases (stroke, diabetes, hypertension, heart disease, tuberculosis, malaria and others) were self-reported.

\subsubsection{Disability}

Disability was measured using the WHO Disability Assessment Schedule (DAS) 2.0 [27]. This instrument includes 12 questions scored on a four-point scale from 0 (no difficulty) to 4 (extreme difficulty / cannot do). Summative scores of the scale were categorised into four equal quartiles, and participants belonging to the last quartile were categorised as functionally disabled. The WHO-DAS was previously used and validated in a study conducted in India [28].

\subsection{Data Analysis}

All statistical analyses were performed using SPSS (IBM Version 25, New York, NY, USA) and STATA (StataCorp LLC Version 15, Lakeway Drive, TX, USA). Descriptive analysis of the sociodemographic variables was performed using different social network 
typologies. The chi-square test and one way ANOVA was used to examine and find the differences of each social networks with the categorical and continuous demographic variables, respectively. Logistic regression was performed to analyze the association between factors and outcomes, and the odds ratio with a $95 \%$ confidence interval (CI) was calculated. Depression and anxiety scores were computed to estimate the prevalence of common mental health conditions among people belonging to different social network types.

\subsection{Ethical Considerations}

Signed informed consent was obtained from all the participants. The authors assert that all procedures contributing to this work comply with the ethical standards of the relevant national and institutional committees on human experimentation and with the Helsinki Declaration of 1975, as revised in 2008. Ethical approval was obtained from (Anonymous) Hospital Institutional Ethics Committee (Registration No. ECR/1153/Inst/ KL/2018, Study Reference Number: RAJH 18003).

\section{Results}

\subsection{Sociodemographic Characteristics}

A total of 997 participants aged $\geq 30$ years were included in the analysis. Table 1 lists the sociodemographic characteristics of the study sample. The majority of participants in the sample were women (63.4\%). $22.9 \%$ of the respondents were aged between 60 and 69 years, $42.8 \%$ were Muslim, 31.2\% had completed primary education and $41.8 \%$ of the respondents belonged to the lowest income group. The mean age of participants was 53.9 (standard deviation $[\mathrm{SD}]=14.2$ ) years. Mean scores of depression and anxiety in the current study were $7.4(\mathrm{~s} . \mathrm{d}=7.3)$ and $5.7(\mathrm{~s} . \mathrm{d}=6.7)$.

The study revealed that $28 \%$ of the participants belonged to the private restricted network type, $26.8 \%$ to the locally integrated, $25.7 \%$ belonged to the wider communityfocused network type, $9.8 \%$ belonged to the family-dependent network type, and $9.7 \%$ belonged to a local self-contained network type. Table 1 presents the characteristics of each social network type.

Table 1. Sociodemographic characteristics by social network typologies.

\begin{tabular}{|c|c|c|c|c|c|c|c|}
\hline \multirow[b]{2}{*}{ Variables } & \multirow[b]{2}{*}{$\begin{array}{c}\text { Total } \\
N=997\end{array}$} & \multicolumn{5}{|c|}{ Social Network Type } & \multirow[b]{2}{*}{$p$ Value * } \\
\hline & & $\begin{array}{c}\text { Locally } \\
\text { Integrated } \\
N=267\end{array}$ & $\begin{array}{c}\text { Local Self- } \\
\text { Contained } \\
\quad N=97\end{array}$ & $\begin{array}{c}\text { Wider } \\
\text { Community } \\
\text { Focused } \\
N=256\end{array}$ & $\begin{array}{c}\text { Family- } \\
\text { Dependent } \\
N=98\end{array}$ & $\begin{array}{c}\text { Private } \\
\text { Restricted } \\
N=279\end{array}$ & \\
\hline Age & $53.9(14.2)$ & $52.7(12.7)$ & $54.4(14.2)$ & $52.4(12.9)$ & $54.1(15.8)$ & $56.2(15.9)$ & $\begin{array}{l}\mathrm{F}=3.09 \\
p=0.015\end{array}$ \\
\hline Gender & & & & & & & $\begin{array}{l}X_{2}=20.7 \\
p<0.000\end{array}$ \\
\hline $\begin{array}{l}\text { Male } \\
\text { Female }\end{array}$ & $\begin{array}{l}365(36.6 \%) \\
632(63.4 \%)\end{array}$ & $\begin{array}{l}125(46.8 \%) \\
142(53.2 \%)\end{array}$ & $\begin{array}{l}28(28.9 \%) \\
69(71.1 \%)\end{array}$ & $\begin{array}{c}94(36.7 \%) \\
162(63.3 \%)\end{array}$ & $\begin{array}{l}36(36.7 \%) \\
62(63.3 \%)\end{array}$ & $\begin{array}{c}82(29.4 \%) \\
197(70.6 \%)\end{array}$ & \\
\hline Income & & & & & & & $\begin{aligned} \mathrm{X}_{2} & =15.008, \\
p & =0.241\end{aligned}$ \\
\hline $\begin{array}{l}1 \text { quartile } \\
2 \text { quartile } \\
3 \text { quartile } \\
4 \text { quartile }\end{array}$ & $\begin{array}{l}417(41.8 \%) \\
108(10.8 \%) \\
245(24.6 \%) \\
227(22.8 \%)\end{array}$ & $\begin{array}{c}109(40.8 \%) \\
38(14.2 \%) \\
58(21.7 \%) \\
62(23.2 \%)\end{array}$ & $\begin{array}{l}40(41.2 \%) \\
11(11.3 \%) \\
26(26.8 \%) \\
20(20.6 \%)\end{array}$ & $\begin{array}{l}98(38.3 \%) \\
30(11.7 \%) \\
67(26.2 \%) \\
61(23.8 \%)\end{array}$ & $\begin{array}{c}49(50 \%) \\
5(5.1 \%) \\
18(18.4 \%) \\
26(26.5 \%)\end{array}$ & $\begin{array}{c}121(43.4 \%) \\
24(8.6 \%) \\
76(27.2 \%) \\
58(20.8 \%)\end{array}$ & \\
\hline Education & & & & & & & $\begin{array}{l}X_{2}=36.9 \\
p=0.002\end{array}$ \\
\hline $\begin{array}{l}\text { None } \\
\text { Did not complete primary } \\
\text { Completed primary } \\
\text { Completed secondary } \\
\text { Completed tertiary }\end{array}$ & $\begin{array}{c}41(4.1 \%) \\
227(22.8 \%) \\
311(31.2 \%) \\
216(21.7 \%) \\
202(20.3 \%)\end{array}$ & $\begin{array}{c}7(2.6 \%) \\
56(21 \%) \\
92(34.5 \%) \\
62(23.2 \%) \\
50(18.7 \%)\end{array}$ & $\begin{array}{c}2(2.1 \%) \\
26(26.8 \%) \\
28(28.9 \%) \\
17(17.5 \%) \\
24(24.7 \%)\end{array}$ & $\begin{array}{c}9(3.5 \%) \\
40(15.6 \%) \\
83(32.4 \%) \\
61(23.8 \%) \\
63(24.6 \%)\end{array}$ & $\begin{array}{c}2(2 \%) \\
22(22.5 \%) \\
28(28.6 \%) \\
23(23.5 \%) \\
23(23.5 \%)\end{array}$ & $\begin{array}{c}21(7.5 \%) \\
83(29.8 \%) \\
80(28.7 \%) \\
53(19 \%) \\
42(15.1 \%)\end{array}$ & \\
\hline Religion & & & & & & & $\begin{array}{c}\mathrm{X}_{2}=17.3 \\
p=0.026\end{array}$ \\
\hline $\begin{array}{l}\text { Christian } \\
\text { Hindu } \\
\text { Muslim }\end{array}$ & $\begin{array}{l}248(24.9 \%) \\
322(32.3 \%) \\
427(42.8 \%)\end{array}$ & $\begin{array}{c}83(31.1 \%) \\
71(26.6 \%) \\
113(42.3 \%)\end{array}$ & $\begin{array}{c}20(20.6 \%) \\
33(34 \%) \\
44(45.4 \%)\end{array}$ & $\begin{array}{c}67(26.2 \%) \\
89(34.8 \%) \\
100(39.1 \%)\end{array}$ & $\begin{array}{l}21(21.4 \%) \\
41(41.8 \%) \\
36(36.7 \%)\end{array}$ & $\begin{array}{l}57(20.4 \%) \\
88(31.5 \%) \\
134(48 \%)\end{array}$ & \\
\hline
\end{tabular}


Table 1. Cont.

\begin{tabular}{|c|c|c|c|c|c|c|c|}
\hline \multirow[b]{2}{*}{ Variables } & \multirow[b]{2}{*}{$\begin{array}{c}\text { Total } \\
N=997\end{array}$} & \multicolumn{5}{|c|}{ Social Network Type } & \multirow[b]{2}{*}{$p$ Value * } \\
\hline & & $\begin{array}{c}\text { Locally } \\
\text { Integrated } \\
N=267\end{array}$ & $\begin{array}{l}\text { Local Self- } \\
\text { Contained } \\
\quad N=97\end{array}$ & $\begin{array}{c}\text { Wider } \\
\text { Community } \\
\text { Focused } \\
N=256\end{array}$ & $\begin{array}{c}\text { Family- } \\
\text { Dependent } \\
N=98\end{array}$ & $\begin{array}{c}\text { Private } \\
\text { Restricted } \\
N=279\end{array}$ & \\
\hline Disability & & & & & & & $\begin{array}{l}X_{2}=79.2 \\
p<0.000\end{array}$ \\
\hline 1 st quartile & $319(32.0 \%)$ & $25(25.5 \%)$ & $115(43.1 \%)$ & $16(16.5 \%)$ & $96(37.5 \%)$ & $67(24.1 \%)$ & \\
\hline 2 nd quartile & $187(18.8 \%)$ & $24(24.5 \%)$ & $48(18 \%)$ & $23(23.7 \%)$ & $56(21.9 \%)$ & $36(12.9 \%)$ & \\
\hline 3 rd quartile & $257(25.8 \%)$ & $28(28.6 \%)$ & $60(22.5 \%)$ & $30(30.9 \%)$ & $68(26.6 \%)$ & $71(25.5 \%)$ & \\
\hline Disabled & $234(23.5 \%)$ & $21(21.4 \%)$ & $44(16.5 \%)$ & $28(28.9 \%)$ & $36(14.1 \%)$ & $105(37.6 \%)$ & \\
\hline Depression & $7.4(7.3)$ & $6.8(7.0)$ & $8(6.9)$ & $6(5.5)$ & $6.6(5.9)$ & $9.4(9.0)$ & $\begin{aligned} \mathrm{F} & =8.92 \\
p & <0.000\end{aligned}$ \\
\hline Anxiety & $5.7(6.7)$ & $4.7(6.2)$ & $6.0(6.1)$ & $5.0(5.9)$ & $5.1(5.1)$ & $7.6(8.1)$ & $\begin{array}{c}\mathrm{F}=8.0 \\
p<0.000\end{array}$ \\
\hline Multimorbidity & & & & & & & $\begin{array}{l}X_{2}=17.8 \\
p=0.121\end{array}$ \\
\hline No & $629(63.1 \%)$ & $185(69.3 \%)$ & $63(64.9 \%)$ & $163(63.7 \%)$ & $61(62.2 \%)$ & $157(56.3 \%)$ & \\
\hline One chronic condition & $265(26.6 \%)$ & $61(23 \%)$ & $26(26.8 \%)$ & $69(27 \%)$ & $29(29.6 \%)$ & $80(28.7 \%)$ & \\
\hline Two chronic condition & $85(8.5 \%)$ & $17(6.4 \%)$ & $8(8.3 \%)$ & $20(7.8 \%)$ & $5(5.1 \%)$ & $35(12.5 \%)$ & \\
\hline Two or more than three chronic conditions & $18(1.8 \%)$ & $4(1.5 \%)$ & 0 & $4(1.6 \%)$ & $3(3.1 \%)$ & $7(2.5 \%)$ & \\
\hline
\end{tabular}

* One way ANOVA and chi-square tests were used to compare the demographic variables with the different social support networks.

Values are numbers (percentage of the number of participants on the variable in question) or means (standard deviation).

\subsection{Social Network Typologies: Association with Depression}

The overall prevalence of moderate and above depression was $15.7 \%$, as determined based on DASS scores for depression. We observed that $23.3 \%$ of participants with a private restricted network exhibited depressive symptoms, whereas only $9.2 \%$ and $14.6 \%$ of participants within family-dependent and locally integrated social networks exhibited depressive symptoms (Table 1). The findings of logistic regression analysis revealed that the odds of depression were significantly lower in participants with family-dependent, locally integrated, locally self-contained and wider community-focused networks than in those with a private restricted social network. Furthermore, the odds of depression were lower in participants with a family-dependent network than in those with a community-focused network. (Table 2).

Apart from social network typologies, age, sex, income, disability and the presence of multiple morbidities were associated with depression scores. For instance, male respondents were less likely to have higher depression scores when compared to women. Respondents with tertiary education had significantly lower odds of depression scores when compared to people who were uneducated. Findings also showed that higher levels of depression were nine times more likely among participants with disability than those without disability. In addition, higher levels of depression were four times more likely among participants with three or more chronic conditions compared with those without a diagnosed chronic condition (Table 2).

\subsection{Social Network Typologies: Association with Anxiety}

According to DASS scores calculated for anxiety, the overall prevalence of moderate and above anxiety scores in the study sample was $21.5 \%$. We observed that $32.6 \%$ of participants with a private restricted social network exhibited moderate and above anxiety scores, whereas only $16.3 \%$ and $16.1 \%$ of participants with family-dependent and locally integrated social networks exhibited moderate and above anxiety scores, respectively. Table 3 described logistic regression analysis of anxiety with different variables. 
Table 2. Association between social network types and depression.

\begin{tabular}{|c|c|}
\hline Explanatory Variables & Crude Odds Ratio $(95 \% \mathrm{CI}), p$ Value \\
\hline \multicolumn{2}{|l|}{ Social networks } \\
\hline Private Restricted & 1 ref. \\
\hline Family-Dependent & $0.33(0.16-0.70), p=0.004$ \\
\hline Locally integrated & $0.56(0.36-0.87), p=0.010$ \\
\hline Local self-contained & $0.65(0.36-1.19), p=0.163$ \\
\hline Wider community focused & $0.39(0.24-0.63), p=0.000$ \\
\hline Age & $1.02(1.01-1.03), p<0.000$ \\
\hline \multicolumn{2}{|l|}{ Sex } \\
\hline Female & 1 ref. \\
\hline Male & $0.38(0.25-0.57), p<0.000$ \\
\hline \multicolumn{2}{|l|}{ Income } \\
\hline 1st quartile & 1 ref. \\
\hline 2nd quartile & $0.24(0.11-0.54), p=0.001$ \\
\hline 3rd quartile & $0.61(0.39-0.92), p=0.021$ \\
\hline 4th quartile & $0.36(0.22-0.59), p<0.000$ \\
\hline \multicolumn{2}{|l|}{ Education } \\
\hline Uneducated & 1 ref. \\
\hline Did not complete primary & $0.95(0.45-1.97), p=0.888$ \\
\hline Completed primary & $0.38(0.18-0.80), p=0.011$ \\
\hline Completed secondary & $0.32(0.14-0.70), p=0.004$ \\
\hline Completed tertiary & $0.16(0.06-0.40), p<0.000$ \\
\hline \multicolumn{2}{|l|}{ Disability } \\
\hline Not disabled & 1 ref. \\
\hline Disabled & $9.1(6.2-13.2), p<0.000$ \\
\hline \multicolumn{2}{|l|}{ Multimorbidity } \\
\hline No chronic condition & 1 ref. \\
\hline One chronic condition & $2.18(1.47-3.23), p<0.000$ \\
\hline Two chronic condition & $4.65(2.78-7.76), p<0.000$ \\
\hline Three or more than three chronic conditions & $4.27(1.54-11.74), p=0.005$ \\
\hline
\end{tabular}

Table 3. Association between social network types and anxiety.

\begin{tabular}{lc}
\multicolumn{1}{c}{ Explanatory Variables } & Crude Odds Ratio (95\% CI), $p$ Value \\
\hline Social networks & 1 ref \\
$\quad$ Private Restricted & $0.40(0.22-0.73), p=0.003$ \\
Family-Dependent & $0.40(0.26-0.60), p=0.000$ \\
$\quad$ Locally integrated & $0.50(0.29-0.88), p=0.016$ \\
$\quad$ Local self-contained & $0.44(0.29-0.66), p=0.000$ \\
$\quad$ Wider community focused & $1.01(1.00-1.02), p=0.05$ \\
\hline Age & 1 ref \\
\hline Sex & \\
Female & 1 ref \\
Male & $0.37(0.26-0.53), p<0.000$ \\
\hline Income & \\
1st quartile & $0.68(0.40-1.15), p=0.153$ \\
2nd quartile & $0.65(0.44-0.96), p=0.031$ \\
3rd quartile & $0.57(0.38-0.86), p=0.007$ \\
4th quartile &
\end{tabular}


Table 3. Cont.

\begin{tabular}{|c|c|}
\hline Explanatory Variables & Crude Odds Ratio (95\% CI), $p$ Value \\
\hline \multicolumn{2}{|l|}{ Education } \\
\hline Uneducated & 1 ref \\
\hline Did not complete primary & $0.64(0.32-1.28), p=0.207$ \\
\hline Completed primary & $0.58(0.29-1.15), p=0.120$ \\
\hline Completed secondary & $0.36(0.17-0.74), p=0.006$ \\
\hline Completed tertiary & $0.22(0.10-0.48), p<0.000$ \\
\hline \multicolumn{2}{|l|}{ Disability } \\
\hline Not disabled & 1 ref \\
\hline Disabled & $5.3(3.8-7.4), p<0.000$ \\
\hline \multicolumn{2}{|l|}{ Multi-morbidity } \\
\hline No chronic condition & 1 ref \\
\hline One chronic condition & $2.03(1.43-2.87), p<0.000$ \\
\hline Two chronic condition & $4.28(2.65-6.92), p<0.000$ \\
\hline Three or more than three chronic conditions & $6.94(2.7-18.03), p<0.000$ \\
\hline
\end{tabular}

The findings of the logistic regression analysis revealed that the odds of anxiety were significantly lower in participants with family-dependent, locally integrated, locally selfcontained and wider community-focused networks than in those with a private restricted social network. Further, anxiety was likely to be lower for educated male respondents who were in the higher income quartiles.

\section{Discussion}

This study examined social network typologies and their association with depression and anxiety using a cross-sectional household survey of adults aged $\geq 30$ years in Kerala, India. The study informed that an educated male belonging to higher income quartiles, without any disability, has lower odds of depression and anxiety. Private restricted (28\%), locally integrated (26.8\%), and wider community-focused (26\%) network typologies were the most prevalent in the studied population. Most importantly, the individuals belonging to locally integrated $(10.6 \%)$ and family-dependent $(9.2 \%)$, network types had lower levels of depression compared with those belonging to the private restricted $(23 \%)$ network type. This finding agrees with a population-based cohort study including older people aged $\geq 65$ years in India [29]. Our study also found that among people within a locally integrated network type, only $9 \%$ were aged $<70$, while $20 \%$ of people within a private restricted network type were aged above 70 . For people aged above 70 years, their higher functional disability acted as a barrier to accessing health-promoting networks and limiting them to private restricted networks.

A cross-sectional study conducted in eight low-income and developing countries (including India) reported similar findings. People belonging to the private restricted network type had a higher risk of depression than those belonging to integrated social network (family dependent and locally integrated) types [14]. However, observations made in a Western context found out that while people in locally integrated networks have the lowest risk of mental health issues such as depression and loneliness, people within a family-dependent network type have higher odds of depression [30,31]. However, in the current study, the lowest risk of depression was seen in the family-dependent network type. This discrepancy could be explained in terms of the limited number of family connections in the Western context compared to the Eastern. For instance, a person in Kerala looking for familial interactions is more likely to have access to them by virtue of higher average household size (average size of 4.8), compared to small average household sizes in European countries (average size range is from 1.9-2.4) [32]. Further, better financial back-ups and more robust social security systems in the Western context aid in accessing paid online supports, while weaker social security systems and lower wages in India 
force people to depend mainly on family in case of need [33]. However, further studies in countries with medium household sizes would be required to affirm this association.

Second to family dependent networks, belonging to a locally integrated network, characterised by social cohesion has the potential to protect people from anxiety or depression. The components of social cohesion: trust, safety and participation [34] can modulate anxiety and depression in the people who share the collectivist value system [35]. Kerala State's social welfare system has heavily invested in locally integrated networks, introducing a participatory bottom-up people's planning approach [36]. Most economical and healthrelated initiatives, such as livelihood promotion and poverty eradication, self-help and neighbourhood groups-based economic engagements, and community health initiatives are navigated through these networks. People belonging to private restricted networks are excluded from many of these social welfare schemes, as most implementations are linked to their participation in these bodies. A cross-sectional study conducted among older people aged $\geq 60$ years in rural Uttar Pradesh, India, demonstrated similar findings in that better social ties with friends and neighbours were protective against depression [37].

Our study also showed a strong association between disability, depression and anxiety. Persons with disabilities had nine times higher depression scores and five times higher anxiety scores than persons with no disabilities. Inadequate access of people with a disability could embed them in restrictive social networks, and lack of integration to a health-promoting network is a detrimental factor to an individual's mental health.

A social network can act as a buffer to protect people from depression and anxiety. However, a few other domains modulate adverse outcomes, which require considerations in future studies. For example, the study found that depression was four times more likely among participants with three or more chronic conditions, even if they belonged to family-dependent networks or locally integrated networks.

Some limitations of this study should be considered while interpreting its findings. Because this is a cross-sectional study, we could not derive any causal inferences from the results. However, this study provides insights into the use of PANT in adults aged above 30 years. Further, this study provides details of the quantitative elements of the networks, such as availability and accessibility to various networks. However, it could not look into the qualitative contribution of these networks in providing help and companionship when people are in need. Further studies are required to establish the qualitative aspects of mental health within these networks in providing help and companionship for the people in need.

\section{Conclusions}

Supportive social networks, especially the family and locally integrated networks, act as buffers to protect people with depressogenic cognitive and social structures from adverse mental health outcomes. Thus, planning and developing comprehensive interventions for people in different social network typologies based on their needs will yield positive health outcomes.

Practitioners can use such network typologies to classify patients into different social network types, which will further assist them in planning and implementing specific social interventions crucial for enhancing patients' lives. Tailor-made social and psychological interventions can be planned for those in the restricted support networks to effectively manage risk factors. Future research can focus on testing the effectiveness of such interventions as well. Lastly, policymakers can consider the different social network typologies and corresponding co-occurring needs of the patients for their benefit while planning and implementing policies for them. The pivotal role of the family-dependent network in modulating depression and anxiety provides practitioners with the crucial insight that even individual level interventions should have a household focus. Considering family as the most significant source of social support and investing in strengthening the entire household will produce sustainable positive outcomes in the population. 
Author Contributions: Conceptualization, S.M.D.; methodology, S.M.D.; formal analysis, L.S.; investigation, L.S.; writing-original draft preparation, S.M.D.; writing-review and editing, L.S., K.T., N.C., supervision, S.M.D. All authors have read and agreed to the published version of the manuscript.

Funding: This research was funded by Rajagiri College of Social Sciences (Autonomous).

Institutional Review Board Statement: The study was conducted according to the guidelines of the Declaration of Helsinki, and approved by the Institutional Ethics Committee of Rajagiri Hospital (RAJH18003, 13 June 2018).

Informed Consent Statement: Informed consent was obtained from all subjects involved in the study.

Data Availability Statement: The data that support the findings of this study are available from the corresponding author, S.M.D., upon reasonable request.

Acknowledgments: The authors wish to thank the academic contributors Martin Webber, Department of Social Policy and Social Work, University of York, UK; Roz Austin, Department of Social Policy and Social Work, University of York UK; Lynette Joubert, University of Melbourne, Australia; Jacques Joubert, University of Melbourne, Australia; and Meredith Fendt-Newlin, Global Mental Health Consultant, Geneva Area, Switzerland. We acknowledge the support of Community health workers and thank all the participants who were part of the data collection.

Conflicts of Interest: The authors declare no conflict of interest.

\section{References}

1. Sagar, R.; Dandona, R.; Gururaj, G.; Dhaliwal, R.S.; Singh, A.; Ferrari, A.; Dua, T.; Ganguli, A.; Varghese, M.; Chakma, J.K.; et al. The burden of mental disorders across the states of India: The Global Burden of Disease Study 1990-2017. Lancet Psychiatry 2020, 7, 148-161. [CrossRef]

2. World Health Organization. Mental Health: A Call for Action by World Health Ministers. Available online: https://www.who. int/mental_health/advocacy/en/Call_for_Action_MoH_Intro.pdf (accessed on 6 August 2020).

3. Werner-Seidler, A.; Afzali, M.H.; Chapman, C.; Sunderland, M.; Slade, T. The relationship between social support networks and depression in the 2007 National Survey of Mental Health and Well-being. Soc. Psychiatry Psychiatr. Epidemiol. 2017, 52, 1463-1473. [CrossRef] [PubMed]

4. Fiori, K.L.; Antonucci, T.C.; Cortina, K.S. Social Network Typologies and Mental Health Among Older Adults. J. Gerontol. Ser. B 2006, 61, P25-P32. [CrossRef] [PubMed]

5. Palinkas, L.A.; Wingard, D.L.; Barrett-Connor, E. The biocultural context of social networks and depression among the elderly. Soc. Sci. Med. 1990, 30, 441-447. [CrossRef]

6. Domènech-Abella, J.; Mundó, J.; Haro, J.M.; Rubio-Valera, M. Anxiety, depression, loneliness and social network in the elderly: Longitudinal associations from The Irish Longitudinal Study on Ageing (TILDA). J. Affect. Disord. 2019, 246, 82-88. [CrossRef]

7. Ojagbemi, A.; Gureje, O. Typology of Social Network Structures and Late-Life Depression in Low- and Middle-Income Countries. Clin. Pract. Epidemiol. Ment. Health 2019, 15, 134-142. [CrossRef]

8. Lau, Y.W.; Vaingankar, J.A.; Abdin, E.; Shafie, S.; Jeyagurunathan, A.; Zhang, Y.; Magadi, H.; Ng, L.L.; Chong, S.A.; Subramaniam, M. Social support network typologies and their association with dementia and depression among older adults in Singapore: A cross-sectional analysis. BMJ Open 2019, 9, e025303. [CrossRef]

9. Costa, A.G.D.; Ludermir, A.B. Transtornos mentais comuns e apoio social: Estudo em comunidade rural da Zona da Mata de Pernambuco, Brazil. Cad. Saúde Públ. 2005, 21, 73-79. [CrossRef]

10. Brummett, B.H.; Mark, D.; Siegler, I.C.; Williams, R.B.; Babyak, M.A.; Clapp-Channing, N.E.; Barefoot, J.C. Perceived Social Support as a Predictor of Mortality in Coronary Patients: Effects of Smoking, Sedentary Behavior, and Depressive Symptoms. Psychosom. Med. 2005, 67, 40-45. [CrossRef]

11. Holt-Lunstad, J.; Uchino, B.N. Social support and health. In Health Behavior: Theory, Research, and Practice; Glanz, K., Rimer, B.K., Viswanath, K.V., Eds.; Jossey-Bass: San Francisco, CA, USA, 2015; pp. 183-204.

12. Saju, M.D.; Nukala, L.; Shekhar, R.; Gomez, K.; Varghese, B.M.; Benny, A.M.; Scaria, L.; Prabhu, S.; Jotheeswaran, A.T. Cohort profile: Social well-being and determinants of health study (SWADES), Kerala, India. BMJ Open 2020, 10, e032803. [CrossRef]

13. Wenger, G. A network typology: From theory to practice. J. Aging Stud. 1991, 5, 147-162. [CrossRef]

14. Thiyagarajan, J.A.; Prince, M.; Webber, M. Social support network typologies and health outcomes of older people in low and middle income countries-A 10/66 Dementia Research Group population-based study. Int. Rev. Psychiatry 2014, 26, 476-485. [CrossRef] [PubMed]

15. Gallegos-Carrillo, K.; García-Peña, C.; Mudgal, J.; Romero, X.; Durán-Arenas, L.; Salmerón, J. Role of depressive symptoms and comorbid chronic disease on health-related quality of life among community-dwelling older adults. J. Psychosom. Res. 2009, 66, 127-135. [CrossRef] [PubMed] 
16. Gunzler, U.; Sajatovic, M.; McCormick, R.; Perzynski, A.; Thomas, C.; Kanuch, S.; Cassidy, K.A.; Fuentes-Casiano, E.; Dawson, N.; Perszynski, A. Psychosocial Features of Clinically Relevant Patient Subgroups With Serious Mental Illness and Comorbid Diabetes. Psychiatr. Serv. 2017, 68, 96-99. [CrossRef] [PubMed]

17. An, S.; Jung, H.; Lee, S. Moderating Effects of Community Social Capital on Depression in Later Years of Life: A Latent Interaction Model. Clin. Gerontol. 2018, 42, 70-79. [CrossRef] [PubMed]

18. Yamaguchi, M.; Inoue, Y.; Shinozaki, T.; Saito, M.; Takagi, D.; Kondo, K.; Kondo, N. Community Social Capital and Depressive Symptoms Among Older People in Japan: A Multilevel Longitudinal Study. J. Epidemiol. 2019, 29, 363-369. [CrossRef]

19. Wu, Y.-H.; White, K.; Fleischer, N.L.; Cai, B.; Chen, S.-C.; Moore, S. Network-based and cohesion-based social capital and variations in depressive symptoms among Taiwanese adults. Int. J. Soc. Psychiatry 2018, 64, 726-736. [CrossRef] [PubMed]

20. Sadock, B.J.; Sadock, V.A.; Ruiz, P. Comprehensive Textbook of Psychiatry, 9th ed.; Wolters Kluwer Lippincott Williams and Wilkins: Philadelphia, PA, USA, 2017; p. 1649.

21. Lovibond, S.H.; Lovibond, P.F. Manual for the Depression Anxiety Stress Scales; Psychology Foundation of Australia, 2nd ed. Available online: http:/ / www2.psy.unsw.edu.au/dass / (accessed on 8 October 2020).

22. Akin, A.; Cetin, B. The Depression Anxiety and Stress Scale (DASS): The Study of Validity and Reliability. Edu. Sci. Theory Pract. $2007,7,241-268$.

23. Venkatarao, E.; Iqbal, S.; Gupta, S. Stress, anxiety \& depression among medical undergraduate students \& their socio-demographic correlates. Indian J. Med. Res. 2020, 141, 354-357. [CrossRef]

24. Kumar, K.S.; Akoijam, B.S. Depression, anxiety and stress among higher secondary school students of Imphal, Manipur. Indian J. Community Med. 2017, 42, 94-96. [CrossRef]

25. Ashida, S.; Heaney, C.A. Differential Associations of Social Support and Social Connectedness with Structural Features of Social Networks and the Health Status of Older Adults. J. Aging Health 2008, 20, 872-893. [CrossRef]

26. Lal, A.; Thomas, J. Prediction of travel time on undivided rural roads. Int. J. Eng. Res. Tech. 2014, 3, 951-954.

27. World Health Organization. Measuring Health and Disability: Manual for WHO Disability Assessment Schedule WHO DAS 2.0; Üstün, T.B., Ed.; World Health Organization: Geneva, Switzerland, 2010.

28. Rai, S.K.; Ramadass, S.; Gupta, S.K.; Kant, S.; Wadhwa, S.; Sood, M.; Sreenivas, V. Prevalence of disability and its association with sociodemographic factors and quality of life in a rural adult population of northern India. Natl. Med. J. India 2018, 31, 268-273. [CrossRef] [PubMed]

29. Santini, Z.I.; Koyanagi, A.; Tyrovolas, S.; Haro, J.M.; Fiori, K.L.; Uwakwa, R.; Thiyagarajan, J.A.; Webber, M.; Prince, M.; Prina, M. Social network typologies and mortality risk among older people in China, India, and Latin America: A 10/66 Dementia Research Group population-based cohort study. Soc. Sci. Med. 2015, 147, 134-143. [CrossRef]

30. Wenger, G.C. Social networks and the prediction of elderly people at risk. Aging Ment. Health 1997, 1, 311-320. [CrossRef]

31. Golden, J.; Conroy, R.M.; Bruce, I.; Denihan, A.; Greene, E.; Kirby, M.; Lawlor, B.A. Loneliness, social support networks, mood and wellbeing in community-dwelling elderly. Int. J. Geriatr. Psychiatry 2009, 24, 694-700. [CrossRef] [PubMed]

32. United Nations, Department of Economic and Social Affairs, Population Division. World Urbanization Prospects: The 2014 Revision; United Nations, Department of Economic and Social Affairs, Population Division: New York, NY, USA, 2014.

33. International Labour Organization. World Social Protection Report; Building Economic Recovery, Inclusive Development and Social Justice. Available online: https://www.ilo.org/wcmsp5/groups/public/---dgreports/---dcomm/documents/ publication/wcms_245201.pdf (accessed on 1 June 2021).

34. Kulkarni, R.S.; Shinde, R.L. Depression and Its Associated Factors in Older Indians: A Study Based on Study of Global Aging and Adult Health (SAGE). J. Aging Health 2015, 27, 622-649. [CrossRef]

35. Saju, M.; Benny, A.M.; Allagh, K.P.; Joseph, B.; Thiyagarajan, J.A. Relationship between neighbourhood cohesion and disability: Findings from SWADES population-based survey, Kerala, India. F1000Research 2020, 9, 700. [CrossRef] [PubMed]

36. Mohanakumar, S. Decentralisation in Kerala: People's Plan. Econ. Polit. Wkly. 2003, 38, 3214-3232.

37. Singh, L.; Singh, P.K.; Arokiasamy, P. Social Network and Mental Health Among Older Adults in Rural Uttar Pradesh, India: A Cross-Sectional Study. J. Cross-Cult. Gerontol. 2016, 31, 173-192. [CrossRef] 